\title{
Sistema de Informação de Saúde: A Epidemiologia e a Gestão de Serviço
}

\section{Padrão de qualidade de um sistema de informação}

A utilização de sistemas de informações enquanto instrumento de definição do perfil epidemiológico, ações de planejamento e avaliação de serviço, passa primeiramente pela avaliação da qualidade dos dados e informações geradas.

Para garantir a confiabilidade de sua utilização nos processos de decisão o Centro de Informações de Saúde, vem pesquisando a qualidade dos dados e sistematizando rotinas que permitam identificar o grau de alcance dos objetivos estabelecidos para cada sistema e acompanhando o grau de entendimento do conceito de suas variáveis. Como exemplo, citamos o trabalho, em cooperação técnica com a Fundação SEADE, relativo a coleta do dado diagnóstico do sistema AIH.

Parece-nos claro que a questão da qualidade da informação está intrinsecamente vinculada à sua utilização na gestão do Sistema de Saúde. $O$ avanço dos recursos de informática tem permitido avaliação da coleta de dados e o retorno das informações em tempo hábil às tomadas de decisões.

A expectativa de que as informações só podem ser utilizadas após a devolução pelos órgãos estaduais ou nacionais, tem diminuído com a descentralização da gestão do Sistema de Saúde. Os sistemas de informação tem sido moldados para serem tratados no nível local verificando-se o aumento de sua utilização enquanto instrumento de reorganização e definição das ações de saúde.

* Coordenadora de Informática de Saúde da Secretaria de Estado da Saúde/São Paulo 
Com o exposto acima não eximimos o Estado de seu papel de gerente maior, assumindo a responsabilidade na devolução de dados gerados fora do município, mas referente a residentes no mesmo.

\section{O atual sistema de informação hospitalar}

Desde janeiro de 1994 as informações da AIH - Autorização de Informação Hospitalar, instrumento que registra o atendimento hospitalar pelo SUS Sistema Único de Saúde são entregues em meio magnético ao gestor.

A mudança do meio de coleta, de papel para disquete, ampliou de tal forma sua utilização enquanto sistema de informação, que desencadeou um processo de recuperação de utilização do método epidemiológico como um dos fundamentos do planejamento e estabelecimento de uma programação assistencial, em confronto a forte conotação de sistema de pagamento.

O meio magnético muito contribui para a qualidade dos dados. A utilização de parâmetros de aceitação na digitação do código de diagnóstico reduz o número de inconsistências, porém na utilização epidemiológica, o cruzamento de diagnóstico por sexo e faixa etária, tem apresentado problemas. Essa avaliação tem levado ao estabelecimento de rotinas que permitem identificar as AIH(s) com problemas e providenciar sua correção antes do encaminhamento para processamento, garantindo a confiabilidade das informações geradas a partir dessa base de dados.

A elaboração do perfil de atendimento hospitalar tem permitido ao gestor a avaliação de indicadores quantitativos que alertam sobre a qualidade da ação prestada e sua reprogramação, seja no custo dos serviços de diferentes complexidades ou de ações de saúde que envolvam os atendimentos ambulatoriais, de vigilância a ambientes de trabalho ou de saúde coletiva, através da identificação de fatores de risco.

Entre as principais utilizações da informação hospitalar na gestão do serviço de saúde, destacamos as seguintes:

1. organização da demanda entre os diferentes níveis de complexidade dos serviços, a partir da caracterização da necessidade da população, como por exemplo: o estabelecimento de ações ambulatoriais a pacientes de grupo de risco, acompanhamento das ações estabelecidas para o atendimento a doenças crônico-degenerativas, etc.

2. organização do fluxo de acesso em um modelo assistencial hierarquizado e regionalizado, permitindo a utilização racional dos recursos, que atualmente destinam-se ao atendimento à saúde da população como um todo, e não mais de forma carimbada ao atendimento hospitalar.

3. o acompanhamento da resolutividade do serviço através dos clássicos indicadores hospitalares. 
Além das informações acima mencionadas os gestores completam o perfil epidemiológico com informações advindas do perfil sócio-econômico, nascidos vivos, mortalidade e relativas ao meio ambiente. 